
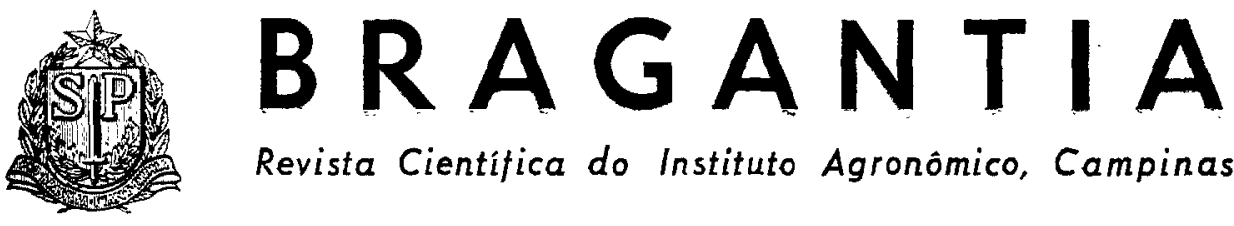

Revista Científica do Instituto Agronómico, Campinas

\title{
MARACAF (IAC 17) E XAVANTES (IAC 18): CULTIVARES DE TRIGO PARA O ESTADO DE SÃO PAULO ( $\left.{ }^{1}\right)$
}

JOAO CARLOS FELfCIO (2), Seçāo de Arroz e Cereais de Inverno, Instituto Agronomico, BENEDITO DE CAMARGO BARROS, Seção de Doenças das Plantas Alimenticias Básicas $e$ Olerícolas, Instituto Biológico, CARLOS EDUARDO DE OLIVEIRA CAMARGO (2), Secão de Arroz e Cereais de Inverno, Instituto Agronómico, e WERNER HORST BAR, Seção de Cereais, Farinhas e Panificação, Instituto de Tecnologia de Alimentos.

\section{RESUMO}

Foram analisados em experimentos localizados nas principais regiões tritícolas do Estado de São Paulo, a produtividade e as reações aos agentes da ferrugem-do-colmo(3) e ferrugem-da-folha, bem como as qualidades de panificação de dois novos cultivares de trigo, Maracaí (IAC 17) e Xavantes (IAC 18), provenientes de cruzamentos artificiais realizados no Intituto Agronômico e obtidos por seleção através do método de genealogia, comparados com os cultivares BH-1146 e IAC 5 . Considerando a média de produçāo de grãos nos anos estudados, o 'Xavantes' foi superior estatisticamente 10 e $14 \%$ pelo teste de Duncan a $5 \%$ em relação, respèctivamente, aos cuitivares BH 1146 e IAC 5, utilizados como controles. O 'Maracai' não apresentou diferença estatística significativa com relação às testemunhas. Relativamente à ferrugem-do-colmo (Puccinia graminis f. $\mathbf{s p}$. tritici), os cultivares apresentaram, nos anos estudados, graus de infecção inferiores aos registrados sobre a testemunha BH 1146. O 'Maracai' apresentou resistência a um maïor número de raças do patógeno ocorrentes em nossas condições. O comportamento desses cultivares com relação à ferrugem-da-folha (P. recondita) assemelhou-se às testemunhas com infeccōes de campo consideradas médias. Nos ensaios de panificação, os dois cultivares evidenciarem valores próximos, apresentando o Xavantes leve superioridade em algumas caracteristicas, porém ambos demonstraram fraca capacidade panificadora quando comparados ao cultivar padrão Tobari 66.

(1) Com verba suplementar do Acordo do Trigo entre as Cooperativas de Produtores Rurais do Vale do Paranapanema e a Secretaria de Agricultura e Abastecimento, atrayés do Instituto Agronômico. Recebido para publicação a 26 de fevereiro de 1980.

(2) Com bolsa de suplementação do CNPq.

(3) Os autores agradecem a colaboração da Dra. Eliza T. Coelho na identificação das raças de ferrugem-do-colmo. 


\section{INTRODUÇÃO}

A produção paulista de trigo (10), representando apenas cerca de $5 \%$ da nacional, vem, a nivel estadual, adquirindo importância nos últimos anos, notadamente na regiāo de Assis, onde se concentra cerca de $90 \%$ da produção, em seqüência à cultura da soja, e onde, apesar das frustrações das safras de 1975 pela geada, granizo, temperatura e umidade elevadas em 1976 e estiagem em 1977, verifica-se ainda expansão da área de semeadura.

Os trabalhos de introdução e melhoramento desenvolvidos no Instituto Agronômico, por CAMARGO ( $\left.{ }^{4}\right)$ têm sido dirigidos no sentido de obter cultivares que tenham boa produtividade e resistência à ferrugem-do-colmo (Puccinia graminis f. sp. tritici) e ferrugem-da-folha (Puccinia recondita).

ALCOVER (1), nos últimos vinte anos, executou um programa de melhoramento genético do trigo, tendo sido selecionadas progênies que originaram os seguintes cultivares: IAC 1, IAC 2, IAC 3, IAC 4, IAC 5, IAC 6, IAC 7, IAC 8, IAC 9, IAC 10 e IAC 11, sendo que - 'IAC 5' é cultivado com sucesso.

Segundo SILVA (13), Fronteira foi a primeira variedade brasileira obtida por cruzamentos ar-

(4) CAMARGO, C. E. O. Relatório número 1 do Projeto FAPESP 72/1467. Melhoramento genético do trigo visando a maior produtividade, resistência às moléstias $e$ melhores qualidades tecnológicas. Campinas, 1973. 68f. (Não publicado) tificiais das variedades Polissu $\times$ Alfredo Chaves 6, distribuída em 1934 no Rio Grande do Sul.

A criação de variedades com resistência às enfermidades mais devastadoras, figura entre as contribuições mais importantes do melhoramento do trigo, devendo-se considerar cada enfermidade um problema independente. Conforme POEHLMAN (9), no caso do trigo deve-se ter maior atenção às ferrugens-do-colmo e da folha.

O objetivo deste trabalho foi estudar o comportamento de dois novos cultivares de trigo (T. aestivum L.) para o Estado de São Paulo, em comparação com os cultivares comerciais BH-1146 e IAC 5.

\section{MATERIAL E MÉTODOS}

O cultivar IAC 17 (Maracaí), obtido pelo método do cruzamento simples, originou-se do hídrido 69/75 IAS-20/IRN-526-63, sendo IAC-20 (IASUL) originário do cruzamento Colônias (Frontana $\times$ Kenya 58) e IRN-526-63, procedente do International Spring Wheat Ruste Nursery de 1963 (yakt. $54 \mathrm{~A}^{3}-$ N. 10B) y $50^{2}-$ - B $8474-5 \mathrm{c}-4 \mathrm{y}-3 \mathrm{c}-1 \mathrm{y}-1 \mathrm{c}$, conduzido pelo Instituto Biológico de São Pauło.

O cultivar IAC 18 (Xavantes), obtido através de retrocruzamentos convergentes (2), originou-se do híbrido $70 / 411$ - BH1146 - S12/BH-1146//BH-1146// BH-1146. O 'BH-1146', obtido através de seleção do híbrido P.G.1/Fronteira-Mentana, no Ins- 
tituto Agronômico de Belo Horizonte, recomendado aos agricultores em 1955, está até hoje em cultivo no Estado de São Paulo, apesar de ser suscetível às raças prevalecentes de ferrugem-do-colmo e de ciclo precoce. O cultivar S-12 originou-se do cruzamento Veranópolis-/Mayo-54/Veranópolis, da Secretaria da Agricultura do Rio Grande do Sul, apresentando resistência a algumas raças do patógeno causador da ferrugem-do-colmo.

Com base nos resultados experimentais do periodo 1976-1980, os dois novos cultivares foram confrontados com o 'BH-1146' e 'IAC 5' (Maringá), nas regiões tritícolas paulistas, encontrando-se as características agronômicas dos quatro cultivares no quadro 1 .

Os ensaios foram delineados em blocos casualizados com quatro repetições por local. Cada parcela constou de cinco linhas de $5 \mathrm{~m}$ de comprimento, espaçadas de $0,20 \mathrm{~m}$ entre si, com separação lateral de $0,60 \mathrm{~m}$ entre as parcelas. Procedeu-se à semeadura com 80 sementes viáveis por metro de sulco, sendo efetuada a colheita da área total das parcelas, ou seja, $5 \mathrm{~m}^{2}$.

Todos os experimentos receberam adubação na semeadura a lanço, constante de $30 \mathrm{~kg} / \mathrm{ha}$ de $\mathrm{N}$, $90 \mathrm{~kg} / \mathrm{ha}$ de $\mathrm{P}_{2} \mathrm{O}_{5}$ e $20 \mathrm{~kg} / \mathrm{ha}$ de $\mathrm{K}_{2} \mathrm{O}$ nas formas de sulfato de amônio, superfosfato simples e cloreto de potássio respectivamente.

Para o estudo do comportamento dos cultivares em relação à ferrugem-do-colmo (P. graminis f. sp. tritici) e ferrugem-da-folha (P. recondita f. sp. tritici), foram feitas avaliações em planta adulta, usando-se a escala modificada de Cobb, empregada no International Rust Nurseries e utilizada por SCHRAM et alii (12): é composta por um número estimativo do ataque da moléstia no colmo e na folha, acrescido de uma letra simbolizando o tipo de reação: $\mathrm{S}=$ suscetível; $\mathrm{MS}=$ moderadamente suscetivel; $\mathrm{M}=$ intermediário; $\mathrm{MR}=$ moderadamente resistente; $\mathrm{R}=$ resistente; $\mathrm{TS}=$ traço suscetível.

Os cultivares estudados foram também testados em casa de vegetação no Centro Nacional de Pesquisas de Trigo - Passo Fundo (RS), em estádio de plântula, individualmente para cada uma das seguintes raças de Puccinia graminis tritici Eriks et Henn: 11, $11 / 65,11 / 74,11 / 78,15 / 65,15 / 71$, $15 / 78,17,17 / 61$ e $17 / 63$.

A altura das plantas de cada cultivar foi medida no campo, por ocasião da colheita, levando em consideração a distância do nível do solo ao ápice da espiga, mantendo-se as plantas esticadas.

$\mathrm{Na}$ determinação do ciclo dos cultivares, foi considerado o número de dias da emergência da plântula até a maturação completa, adotando-se como ciclo precoce maturação até 120 dias, ciclo médio de 121 a 135 dias e, tardio, acima de 136 dias.

Amostras de grãos dos cultivares Maracai e Xavantes, bem como do cultivar padrão Tobari66 , foram analisadas do ponto de vista físico e de panificação. 


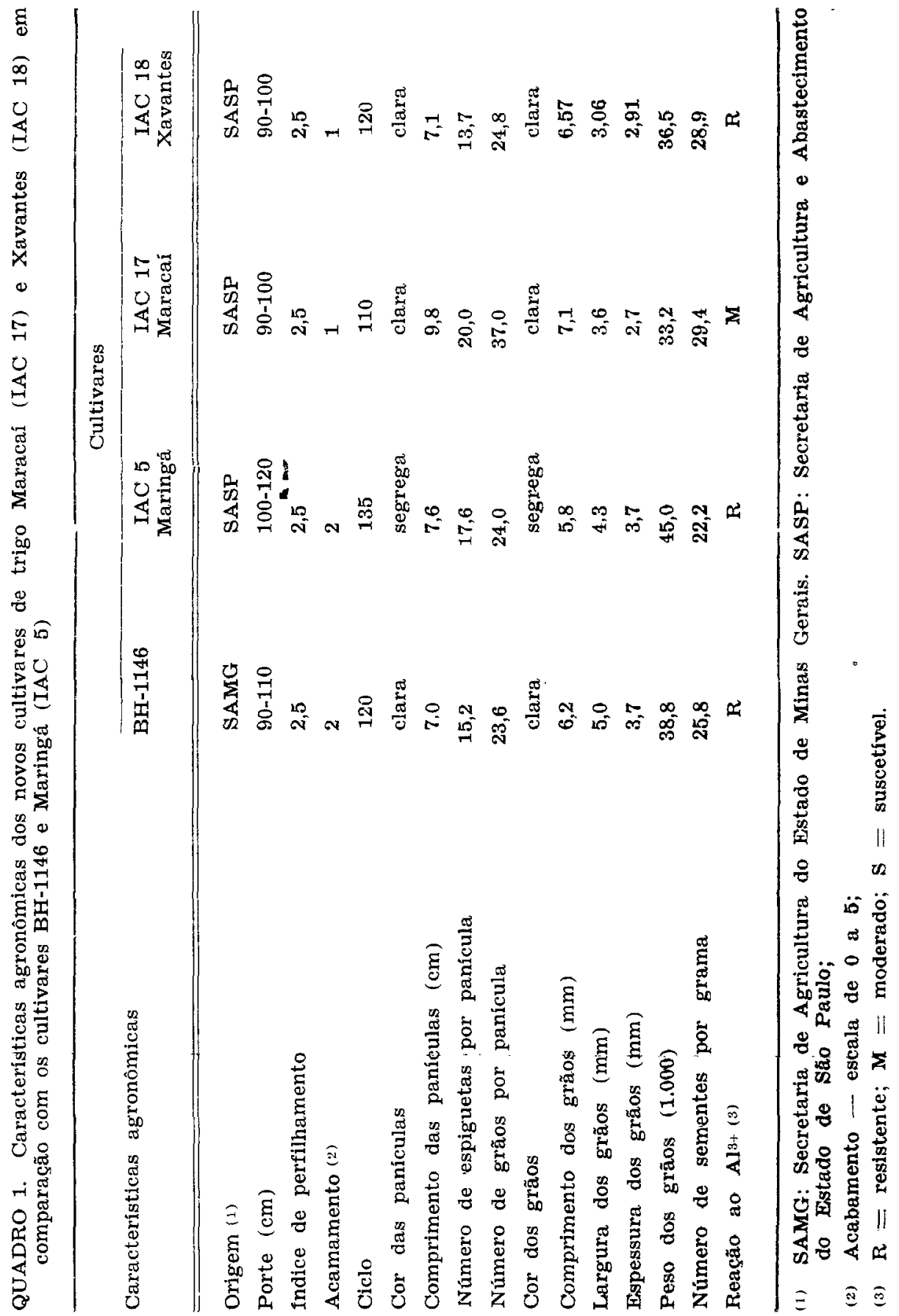


Efetuaram-se análises de ordem física e ensaios correspondentes de panificaçāo com as determinações de indice de Pelshenke (8) e do teor de umidade (7). Nas amostras de farinha obtidas da moagem, determinou-se o índice de intumescimento do glúten $(4,11)$, a resistência da massa à manipulação no farinógrafo e à distensão no extensógrafo $(\boldsymbol{y})$, análises estas que permitem avaliar a capacidade de retenção de gases, considerando-se que, quanto maior a capacidade de retenção, melhor a qualidade do produto.

Determinou-se a atividade amilásica $(\mathbf{7}, \mathbf{1 1})$, que está relacionada com a resistência do miolo, através do amilógrafo, aparelho que registra a viscosidade de uma suspensāo de farinha em água em função da elevação da temperatura à razão de $1,5^{\circ} \mathrm{C} /$ minuto. Uma atividade muito elevada afeta a firmeza do miolo do pão, ao passo que uma atividade amilásica muito baixa conduz a um miolo muito seco e quebradiço.

Nos ensaios de panificação (11), realizou-se o ensaio de pão francês, calculando-se a cifra de panificação, obtida em função do volume do pão referente a 100 gramas de farinha $e$ da porosidade e consistência do miolo. Quanto maior for o valor determinado, melhor a qualidade da farinha.

\section{RESULTADOS E DISCUSSĀO}

Os cultivares Xavantes e Maracaí demonstraram boa capacidade produtiva nos ensaios instalados nas diferentes regiöes tri- tícolas do Estado de Sāo Paulo no período 1976-1980.

As produções médias de grãos dos cultivares Xavantes e Maracaí, comparadas com as obtidas pelos cultivares BH-1146 e IAC 5, amplamente cultivados pelos triticultores paulistas, acham-se no quadro 2 , onde se pode verificar que o 'Xavantes' produziu em média, nesse periodo, $1.711 \mathrm{~kg} / \mathrm{ha}$, enquanto o $\mathrm{BH}-1146$ e o IAC 5 apresentaram produções de $1.555 \mathrm{e}$ $1.505 \mathrm{~kg} /$ ha respectivamente, o que representa uma produtividade superior 10 e $14 \%$ em relação às testemunhas pelo teste de Duncan.

Para o cultivar Maracaí, a média geral de produçāo nesses anos foi $1.361 \mathrm{~kg} / \mathrm{ha}$, que, comparada aos $1.386 \mathrm{~kg} /$ ha e $1.371 \mathrm{~kg} /$ ha dos cultivares BH-1146 e IAC 5 respectivamente, não apresenta diferença estatistica pelo teste de Duncan.

Os dados de produção apresentados correspondem a produções médias; no período estudado nas duas regiōes triticolas, em quinze experimentos, observou-se uma variação de 863 a $2.463,285$ a 2.513 e 453 a $2.365 \mathrm{~kg} /$ ha para os cultivares Xavantes, IAC 5 e $\mathrm{BH}-1146$ respectivamente. Para o cultivar Maracaí, a variação ocorrida em dezessete experimentos foi 366 a $2.103 \mathrm{~kg} / \mathrm{ha}$, e para o IAC 5 e BH-1146, 285 a 2.205 e 453 a $2.295 \mathrm{~kg} /$ ha respectivamente.

O cultivar Maracaí apresenta um ciclo de 110 dias, portanto precoce em comparação ao 'BH1146' e 'IAC 5' respectivamente, com 120 e 135 dias da germinação 


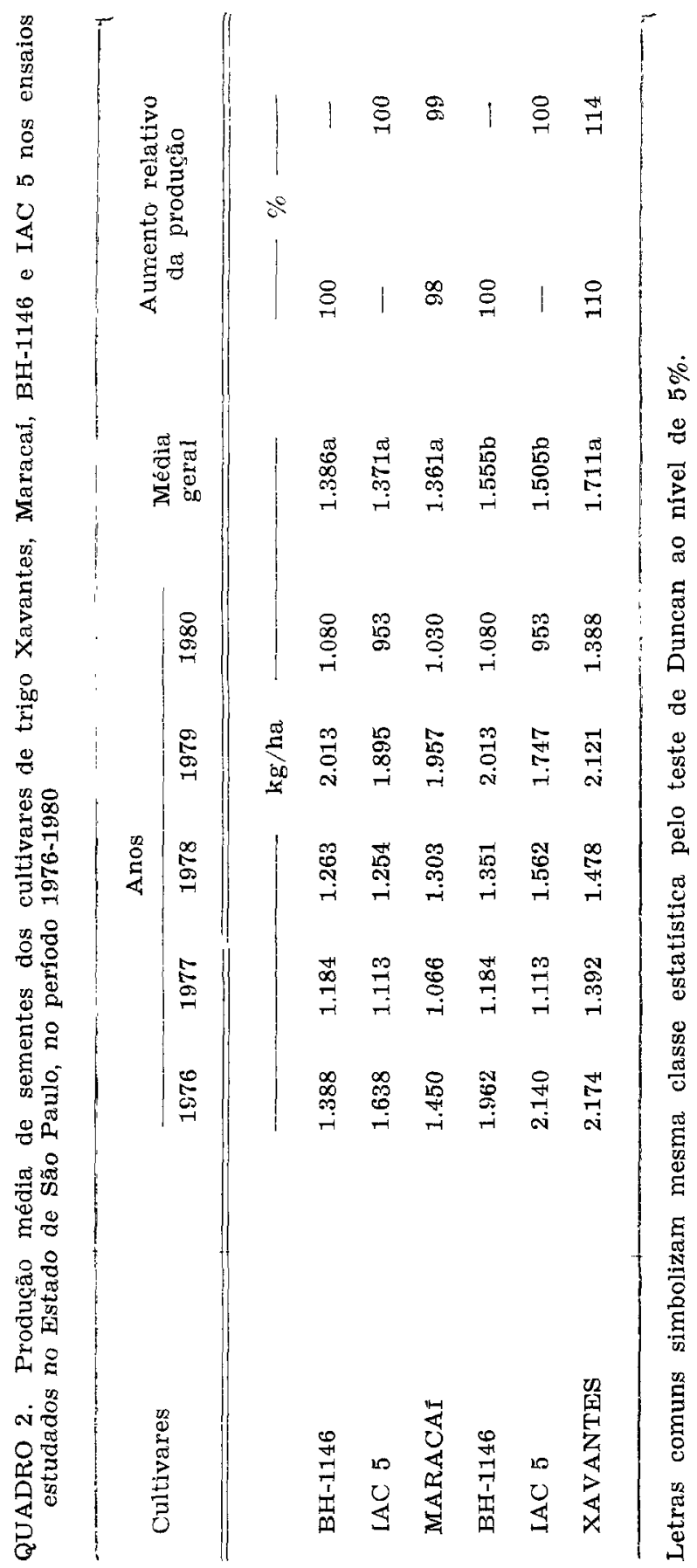


à colheita enquanto que o cultivar Xavantes apresenta ciclo também considerado precoce, 120 dias.

O ciclo precoce dos novos cultivares, principalmente o Maracaí, proporcionará menor período de ocupação da terra com a cultura, possibilitando a semeadura de outras culturas logo após a colheita do trigo com tempo hábil para o preparo do solo.

'Xavantes' e 'Maracaí' apresentam maior resistência ao acamamento que os cultivares $\mathrm{BH}$ 1146 e IAC 5.

Com relação à resistência à ferrugem-do-colmo (Puccinia graminis f. sp. tritici), os dados do quadro 3 demonstram que o cultivar Maracaí apresentou baixos índices de infecção nos ensaios conduzidos na região Sul, em 1976 e 1977, e já em 1978 apresentou uma infecção de $30 \mathrm{~S}$, no início da maturação, enquanto o BH-1146 teve $40 \mathrm{~S}$. Isso se deve a uma grande incidência nesse ano de raça $11 / 74$, à qual o cultivar IAC 17 é suscetível $(5,6)$.

Já na região do Vale do $\mathrm{Pa}$ ranapanema, conforme o quadro 4, tanto o cultivar Maracaí como - Xavantes apresentaram sintomas de suscetibilidade com infecções médias de $13,3 \mathrm{~S}$ e $16,7 \mathrm{~S}$ respectivamente, porém em todos os anos foram inferiores às obtidas pelo BH-1146, cuja média foi 43,3S. Através de levantamento (6), verificou-se a ocorrência, na região, das raças 11/74 e 15/65 em 1976 e 1977 e $11 / 74,15 / 78$ e $17 / 61$ em 1978, às quais os cultivares apresentaram suscetibilidade.
Pelo quadro 5, verifica-se que o cultivar de trigo Xavantes apresentou-se imune às raças $17 \mathrm{e}$ $17 / 61$; resistente às raças $17 / 63$ e 11/65, e moderadamente resistente à raça 11; por outro lado, cv' Maracaí mostrou-se imune às raças $11,11 / 65,15 / 65,17,17 / 63$, ccm pequena mistura de plantas suscetiveis à raça 17/63 e resistentes à raça 15/71.

Com relação à ferrugem-da-folha (P. recondita f. sp. tritici), os dados indicaram que os dois cultivares foram suscetiveis a campo em ambas as regiōes com uma infecção média de 18,3S para - Maracaí e de 20,0S para o Xavantes na região do Paranapanema, comparados a $26,7 \mathrm{~S}$ para o $\mathrm{BH}-1146$ e IAC 5. Na regiåo Sul, os cultivares alcançaram índices de infecção maiores que as testemunhas. Os cultivares foram suscetíveis às raças B4 e B6 que ocorreram com maior freqüência em São Paulo (3) no ano de 1978.

Analisando o quadro 6, verifica-se que os cultivares Maracaí e Xavantes acusaram valores de capacidade de panificação próximos entre si, valores estes inferiores aos apresentados pelo 'Tobari-66', tomado com a finalidade de comparação.

Indices de Pelshenke (I.P.) e de intumescimento (I.I.) alcançados pelos cultivares Xavantes e Maracaí, estão abaixo de $50 \mathrm{mi}$ nutos e de $10 \mathrm{~cm}^{3} / \mathrm{g}$ para as respectivas determinaçōes. Neste caso são cultivares cujas farinhas são de pouca força. 

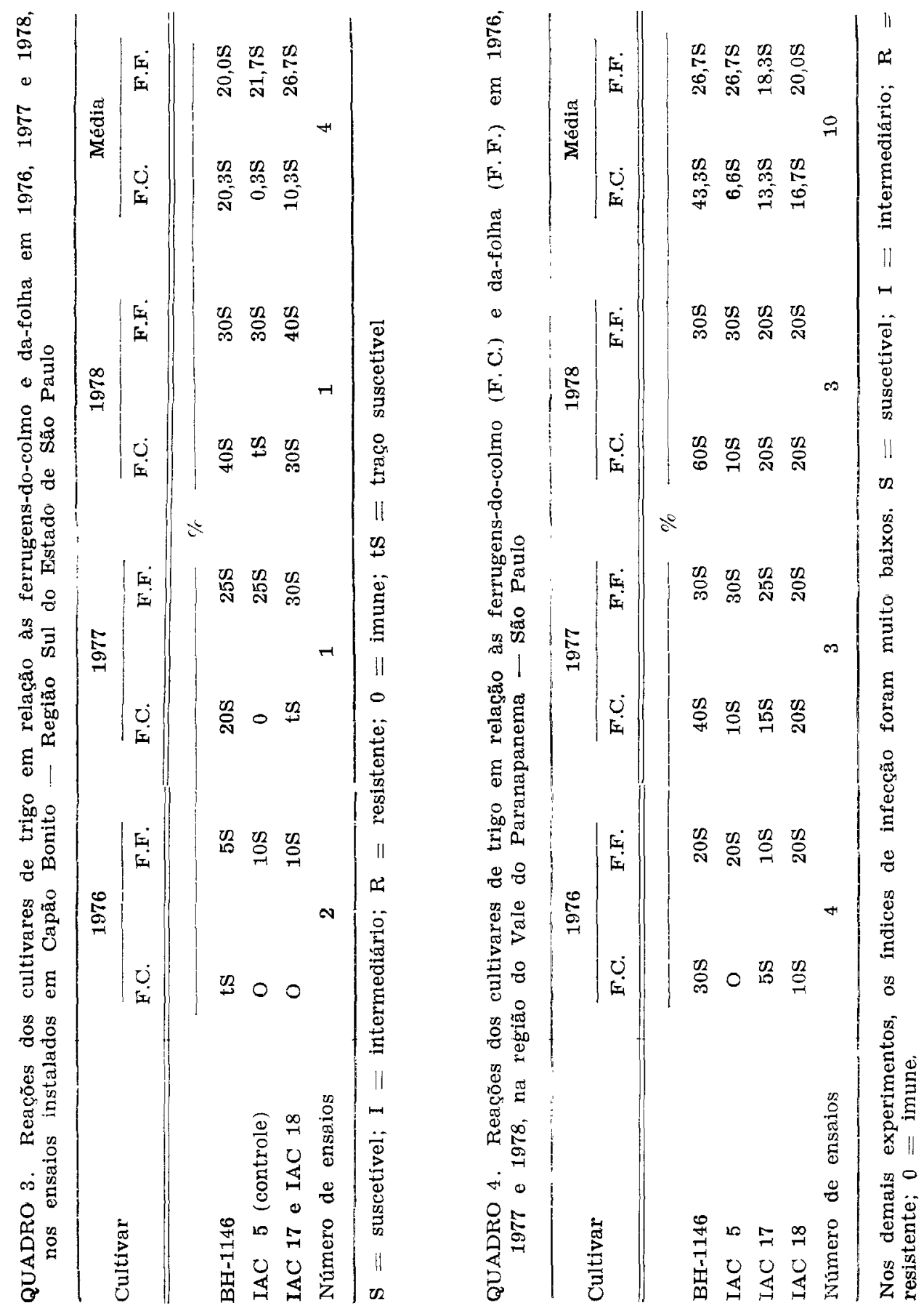


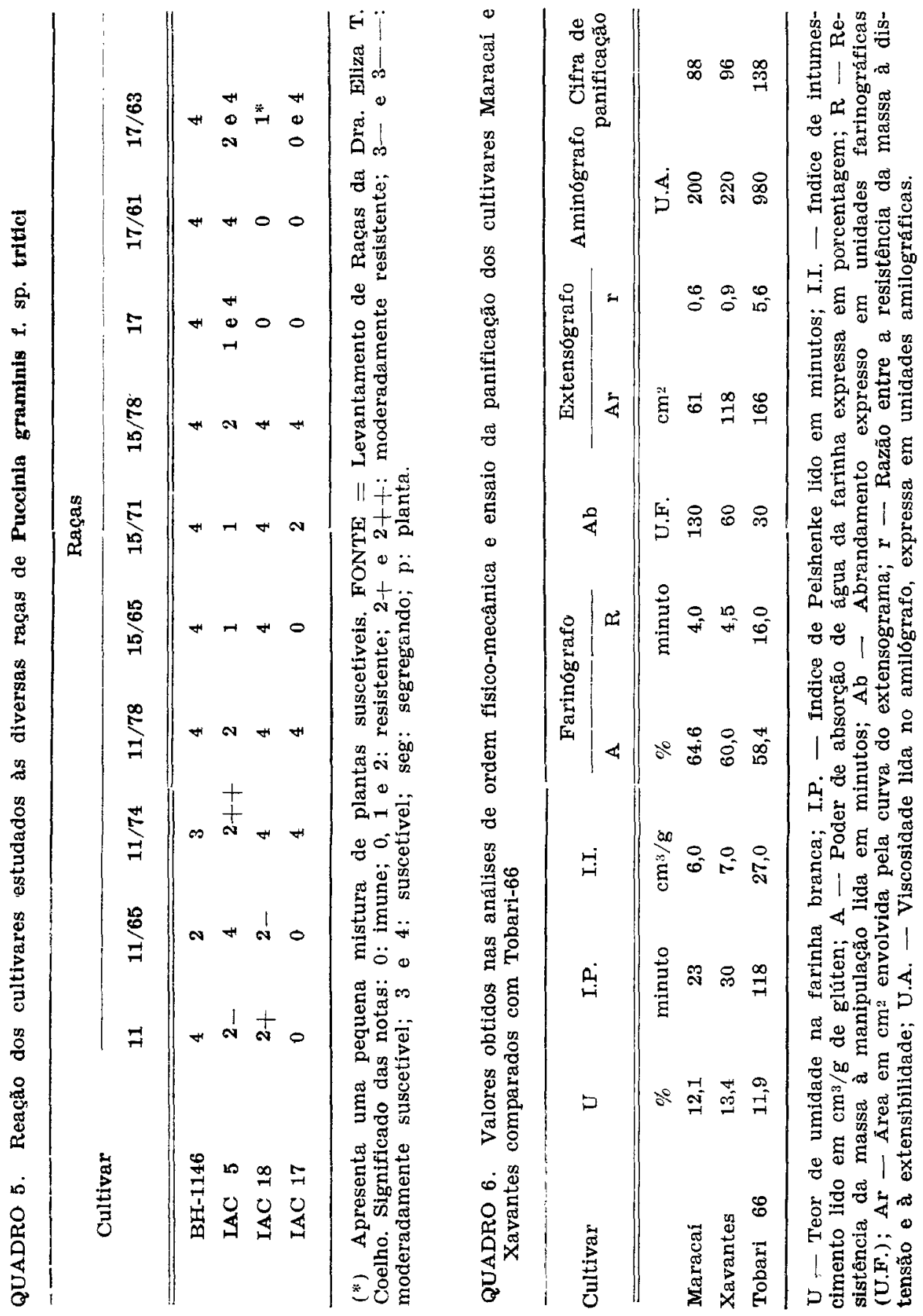


No farinógrafo, os valores de resistência (R) de 4,0 e 4,5 minutos, obtidos respectivamente por 'Maracaí' e 'Xavantes', indicam cultivares fracos. $O$ valor do abrandamento $(\mathrm{Ab})$ é tanto mais elevado quanto maior for a tendência da massa ao amolecimento: o 'Xavantes', portanto, com valor de abrandamento menor que Maracaí, amolece menos, e o 'Tobari-66', menos ainda, caracterizando elevada resistência à manipulação.

O 'Xavantes' acusou no extensógrafo um valor de área (Ar) mais elevado que o Maracaí, o que lhe confere qualidades panificáveis mais pronunciadas, identificando-o como cultivar de valor médio para panificação.

A atividade amilásica foi relativamente alta em ambos os cultivares, com viscosidade máxima alcançada à temperatura de $90^{\circ} \mathrm{C}$ ao redor de 200 U.A., considerada baixa, o que poderá ocasionar um miolo de pão pouco consistente. Nos ensaios de panificação, os dois cultivares acusam valores próximos, estando o Xavantes com valor um pouco acima, demonstrando fraca capacidade panificadora comparada ao "Tobari-66".

\section{CONCLUSÕES}

O presente trabalho permitiu tirar as seguintes conclusões:

1) O cultivar Xavantes apresentou produções superiores e significativas pelo teste de Duncan, em $10 \%$ e $14 \%$, respectivamente, ao 'BH-1146' e 'IAC 5';

2) Não houve diferenças significativas em relação à produção de grãos entre o 'Maracaí' e os controles: 'BH-1146' e 'IAC 5';

3) 'Xavantes' e 'Maracaí' apresentaram, nos anos estudados, graus de infecção de ferrugem-do-colmo inferiores aos registrados pela testemunha $\mathrm{BH}$ -1146. O 'Maracaí' apresentou resistência a maior número de raças do patógeno ocorrentes em nossas condições;

4) 'Maracaí' e 'Xavantes' não diferiram dos cultivares BH-1146 e IAC 5 em relação às reações à ferrugem-da-folha;

5) 'Maracaí' mostrou-se com ciclo mais precoce (110 dias) em relação aos demais (120 a 135 dias);

6) 'Maracaí' e 'Xavantes' apresentaram fraca capacidade panificadora, quando comparados com o cultivar padrão Tobari-66 .

\section{SUMMARY}

MARACAT (IAC 17) AND XAVANTES (IAC 18): WHEAT CULTIVARS (TRITICUM AESTIVUM L.) FOR THE STATE OF SÃO PAULO, BRAZIL

The new cultivars Maracaí (IAC 17) and Xavantes (IAC 18) were selected in the wheat breading program conducted at Instituto Agronomico. They were studied in the main wheat area of the State of São Paulo, compared with the commercial cultivars $\mathrm{BH}-1146$ and IAC 5, in relation to yield, reactions to stem and leaf rusts and to bread quality. 
The results showed that the cultivar Xavantes yielded $10 \%$ and $14 \%$ more than BH-1146 and IAC 5, respectively during the period of 1976 to 1980 . The cultivar Maracai did not differ in yield from the checks during the same period.

The new cultivars evaluated to stem rust presented a low degree of yield infection in relation to $\mathrm{BH}-1146$.

The cultivars Maracai and Xavantes as well as the check were moderately susceptible to leaf rust.

The bread quality trials indicated that there were very few differences between Xavantes and Maracaí. Xavantes was a little superior in some characteristics to Maracai. Both cultivars presented low bread quality when compared with the Mexican wheat cultivar Tobari-66 used as control.

It was possible to indicate Xavantes and Maracaí to be planted commercially in the State of São Paulo based on the results presented in this paper.

\section{REFERENCIAS BIBLIOGRAFICAS}

1. ALCOVER, M. Melhoramento de variedades de trigo em São Paulo. In: ENCONTRO SOBRE TRITICULTURA, Campinas, SP, 1971. 26p.

2. ALLARD, R. W. Principles of plant breeding. New York, John Wileiy \& Sons, Inc., 1960. 381p.

3. BARCELOS, A. L. Ferrugem-da-folha do trigo no Brasil em 1978: raças fisiológicas fontes de resistência, ensaio norte brasileiro. In: REUNIÃo DA COMISSĀO NORTE-BRASILEIRA DE TRIGO, 5., Dourados, MS. 1979. p. 18-26.

4. BAYMA, C. Trigo. Rio de Janeiro. Serviço de Informação Agrícola. Ministério da Agricultura. 1960. 443p.

5. COELHO, E. T. Distribuição e prevalência e novas raças fisiológicas de Puccinia graminis tritici no Brasil, em 1977 e 1978 (parcial). In: REUNLÃO DA COMISSÃO NORTE BRASILEIRA DE TRIGO, 5., Dourados, MS, 1979. p. 1-6.

6. - Ferrugem-do-colmo do trigo no Brasil: levantamento de raças em 1978 e 1979 (parcial) e teste de resistência dos cultivares do ensaio norte brasileiro. In: REUNIĀO DA COMISSÃO NORTE-BRASILEIRA DE PESQUISA DE TRIGO, 6., Curitiba, PR, 1980. p.13-15.

7. KENT-JONES, D. W. \& AMOS, A. J. Modern cereal chemistry. London, 6. ed. Food Trade Press, 2, 1967. 730p.

8. MrXICO. Centro Internacional de Mejoramiento de Maiz y Trigo. Noticiero Cimmyt, México 4(3-4):1-6, 1969.

9. POEHLMAN, J. M. Mejoramiento genetico del trigo. In: —_ Mejoramiento genetico de las cosechas. México, Ed. Limusa S.A., 1974. Item 6, p.123-150.

10. PROGNósTICO - 78/79. São Paulo, Instituto de Economia Agricola, 1978. p.111-113.

11. ROHRLICH \& BRUECKNER. Das Getreide. Berlin, Ed. A. W. Hayn'serber, 1956. 198 p.

12. SCHRAM, W.; FULCO, W. S.; SOARES, M. H. G.; ALMETDA, A. M. P. Resistência de cultivares de trigo em experimentação ou cultivo no Rio Grande do Sul, às principaìs doenças fúngicas. Agronomia Sulriograndense, Porto Alegre, 10:31-39, 1974.

13. SILVA, A. R. da. Melhoramento das variedades de trigo destinadas as diferentes regiões do Brasil. Rio de Janeiro, Serviço de Informação Agrícola do Ministério da Agricultura, 1966. 82p. (Estudos Técnicos, 33) 